\title{
Complete spinal block after spinal anesthesia with low-dose bupivacaine in the elderly
}

\author{
Nguyen Trung Kien ${ }^{1 *}$, Nguyen Truong Giang ${ }^{1}$, Sinh Nguyen $^{2}$, Nguyen Ngoc Thach ${ }^{1}$ and Vo Van Hien ${ }^{1}$ \\ ${ }^{1}$ Vietnam Military Medical University, Vietnam \\ ${ }^{2}$ Harvard Medical School, USA
}

\begin{abstract} 6 days after the incident.

\section{Introduction}

Spinal anaesthesia (SA) can safely provide excellent operating conditions for surgery below the umbilicus. There are many advantages of SA over general anesthesia such as reduction of metabolic stress responses to surgery and anesthesia; decreaseof the risk of venous thromboembolic complications; and avoidance of endotracheal intubation [1]. However, this procedure may be associated with severe potential complications that an anesthetist must be aware of, such as high block or complete spinal block [2]. Here, we report a case of total spinal block in an elderly patient who presented with loss of consciousness and apnea within 2.5 hours after spinal anesthesia with low-dose bupivacaine and fentanyl.
\end{abstract}

Total spinal block after spinal anesthesia with low-dose bupivacaine is a rare complication. Here, we report a case of total spinal block in an elderly patient who presented with loss of consciousness and apnea within 2.5 hours after subarachnoid block with low-dose bupivacaine. She recovered completely and was discharged

\section{Case report}

The patient is an 80 year-old female, $158 \mathrm{~cm}$ tall, $82 \mathrm{~kg}$ who had a 10 -year history of Pakinson disease. She was diagnosed of bleeding in the anal canal, which required an emergency surgery for hemostasis. Her ECG was normal with sinus rhythm; blood pressure was 145/80 $\mathrm{mmHg}$; the respiratory rate was 15 breaths per minutes.

Blood test: Red blood cell $4.22 \times 10^{9} / \mathrm{L}$, hemoglobin $136 \mathrm{~g} / \mathrm{L}$, hematocrit $0.46 \mathrm{~L} / \mathrm{L}$, platelet $199 \mathrm{G} / \mathrm{L}$, albumin $44 \mathrm{~g} / \mathrm{L}$; protein 68 $\mathrm{g} / \mathrm{L}$; creatinin $145 \mu \mathrm{mol} / \mathrm{L}$, ure $5.6 \mathrm{mmol} / \mathrm{L}$; glucose level $5.4 \mathrm{mmol} / \mathrm{L}$; GOT 38 U/L; GPT 36 U/L. Plasma electrolytes were normal (natri 146 $\mathrm{mmol} / \mathrm{L}$; kali $3.4 \mathrm{mmol} / \mathrm{L}$ ). Abdominal ultrasound and chest X-ray were normal.

Intravenous canulation was done with a $18 \mathrm{G}$ needle. The patient was preloaded with Ringer lactat $(10 \mathrm{ml} / \mathrm{kg})$ and continuously mornitored of ECG, heart rate, oxygen saturation $\left(\mathrm{SpO}_{2}\right)$. Her blood pressure was monitored in $2.5 \mathrm{~min}$ interval. Oxygen was given through a face mask at a rate of $6 \mathrm{~L} \cdot \mathrm{min}^{-1}$.

Subarachnoid block was performed at the L3-L4 intervertebral space in the lateral position with $5 \mathrm{mg}$ of bupivacaine and $20 \mu \mathrm{g}$ of fentanyl. The patient was immediately turned to supine position and horizontal plane.

A T6 sensory level block was achieved in $2.5 \mathrm{~min}$. Bromage score was 3 and oxygen saturation was $100 \%$ at that time. Blood pressure fell down from $146 / 82$ to $86 / 62 \mathrm{mmHg}$ at $7.5 \mathrm{~min}$ and $10 \mathrm{mg}$ of ephedrin was intravenous administered.

Ten minutes after intrathecal injection of the drugs, the patient suddenly lost communication and did not response to verbal commands and deep pain stimulation, while blood presure was $123 / 71 \mathrm{mmHg}$. There was no complaint of chest pain or weakness of the upper limbs immediately before losing consciousness. The pupils size and shape were normal and responsive to light. The patient's vital signs were as the following:blood pressure, 123/71 mmHg; heart rate, 67 beats $\mathrm{min}^{-1}$; ECG, sinus rhythm; $\mathrm{SpO}_{2}, 60 \%$. The patient was ventilated through a ventilating mask with a rate of 20 breaths.min ${ }^{-1}$. The patient's $\mathrm{SpO}_{2}$ reached $100 \%$ after 3 minutes of ventilation. She was still unconscious and had no spontaneous breathing. The patient was intubated easily without muscle relaxant and no larynx reflex.

Two and half hour after spinal anesthesia, the patient had larynx reflex and responsed to verbal commands and pain stimulation. The endotracheal tube was extubated and the patient recovered after 2.5 hours. The patient could raise the legs with full flexion of knees and feet and answer accurately doctor's questions. No sensory block was seen with the ice test on the skin.

She was discharged after 6 days of treatments.

\section{Discussion}

Some conditions may lead to unconsciousness after spinal anesthesia in this patient.

Diabitic coma was not the reason in this patient because the blood

Correspondence to: Dr. Nguyen Trung Kien, Department of Anesthesia Vietnam Military Medical University, No. Hospital 103, 261 Phung Hung road, HaDong distric, Ha Noi city, Postal Code: 10000, Vietnam, Tel: +84979800922 , E-mail: drkien103@gmail.com

Key words: complete spinal anesthesia, loss of consciousness, apnea, elderly

Received: September 01, 2015; Accepted: October 09, 2015; Published: October 12,2015 
glucose concentration was $5.4 \mathrm{mmol}$. litre ${ }^{-1}$ Moreover, she did not have the history of epileptic seizure and this cause may be eliminated, too. The normal ECG preoperative and intraoperative period indicated that the event could not explained by arrhythmias.

Since no intravenous medicine was given, inadvertent administration of intravenous sedative or narcotic drugs was excluded as the cause of the loss of consciousness According to Pescod et al. [3], although the addition of opioid improves the quality and duration of analgesia, it also increases risks. It is safe to add 10 to $20 \mu \mathrm{g}$ of fentanyl intrathecally. Patients might be at risk of early (within 2 hours) and late (within 6 to 12 hours) respiratory depression if receiving a single spinal dose of morphine ( 0.1 to $0.3 \mathrm{mg}$ ), respectively. Opioids produce intense visceral analgesia and may prolong sensory blockade without affecting motor or sympathetic function. The major sites of action are the opiate receptors within the second and third laminae of the substantia gelatinosa in the dorsal horn of the spinal cord.

Another the reason for the loss of consciousness after spinal anesthesia is subdural block, which could be suggested by the delayed onset of apnea. However, the cerebral spinal fluid was easily aspirated in this patient before intrathecal injection of the mixture of bupivacaine and fentanyl, indicating that that unconsciousness and apnea was unlikely due to subdural block in this case.

Lipophilic agents such as fentanyl have a much more localized effect than hydrophilic agents such as the hydrophilic opioid morphine. Fentanyl have a rapid onset of action and an effective duration greater than 6 hours (morphine lasts 6-24 hours) [1]. Side effects include respiratory depression (which may occur late with hydrophilic agents), nausea, vomiting, pruritus, and urinary retention. However, only $20 \mu \mathrm{g}$ fentanyl (combined with $5 \mathrm{mg}$ bupivacaine heavy) was given intrathecally to this patient. In addition, she had apnea at the same time with loss of consciousness. Although we administered $0.2 \mathrm{mg}$ of intravenous naloxon, an opioid antagonist, the patient had no signs of spontaneous ventilation and consciousness, which indicates that the inhibition of the respiratory center was not the cause of apnea.
The sudden loss of consciousness during the procedure could be attributed to intra-operative stroke. The patient's blood pressure significantly increased, with systolic pressure reached 180 to 210 mmHg in 45 min after SA (Table 1), without any awake signs (sweat, tearing, cough reflex). However, both of her pupils were about $3 \mathrm{~mm}$ wide and still responsive to light. The postoperativebrain CTscan was normal, as shown by no space-occupying intracranial lesion which could be accounted for the intra-operative loss of consciousness. According to Bhati et al. [4], loss of consciousness is usually due to severe hypotension from a high spinal block with a large dose of local anesthetic. The signs of cephalad extension of the block are usually slower than with an immediate total spinal block, and patients may complain of dyspnea, weakness of the arms or dysarthria. There may be no warning before the loss of consciousness suddenly occurs sometime after the block has been inserted $[4,5]$. In this patient, loss of consciousness and apnea occurred $10 \mathrm{~min}$ after spinal anesthesia, while blood pressure deeply decreased to $86 / 62 \mathrm{mmHg}$ ealier, at $7.5 \mathrm{~min}$ after spinal anesthesia (Table 1). The pressure decreased to approximately $41 \%$ of the baseline value.

Spinal anesthesia can cause hypotension, depending on the dose used. According to Barash et al, drug doses and volume appear to be relatively unimportant in predicting the spread of hyperbaric local anesthetic solutions injected in the horizontal position [1]. Increasing the dose and volume of hyperbaric tetracaine, while holding concentration constant, does not affect block height when doses between 7.5 and $15 \mathrm{mg}$ are used. But, the dose for elderly people may be lower to reach to the same sensory level, indeed. Methods commonly used to prevent or treat hypotension, include fluid preloading, the use of hyperbaric bupivacaine, positioning to relieve aortocaval compression and vasopressor therapy. In the study by Tarkkila $e t$ al., hypotension during spinal anesthesia results principally from the preganglionic sympathetic blockade [6]. Systemic vascular resistance decreases as a result of the reduction in sympathetic tone of the arterial circulation, which leads to peripheral arterial vasodilatation. The extent of effects depends on the number of spinal segments involved.

Table 1. Patient progress and vital signs after subarachnoid block.

\begin{tabular}{|c|c|c|c|c|}
\hline $\begin{array}{l}\text { Time after subarachnoid } \\
\text { block (minutes) }\end{array}$ & $\begin{array}{l}\text { Systolic/diastole pressure } \\
(\mathrm{mmHg})\end{array}$ & Heart rate & $\mathrm{SpO}_{2}(\%)$ & Notes \\
\hline 1 & $146 / 82$ & 82 & 100 & Face mask oxygen, flow rate $=3 \mathrm{~L} \mathrm{~min}-1$ \\
\hline 2.5 & $128 / 72$ & 80 & 100 & Sensory level reached at $\mathrm{T} 6$ \\
\hline 5 & $110 / 62$ & 76 & 100 & Surgery for hemostasis started \\
\hline 6 & $121 / 66$ & 66 & 100 & \\
\hline 7.5 & $86 / 62$ & 58 & 95 & Injection of $10 \mathrm{mg}$ of ephedrin \\
\hline 10 & $123 / 71$ & 67 & 60 & Unconsciousness, apnoea \\
\hline 12 & $132 / 76$ & 75 & 98 & \multirow[t]{3}{*}{ Ventilation through a ventilating mask, with $100 \%$ of oxygen } \\
\hline 15 & $135 / 72$ & 76 & 99 & \\
\hline 20 & $140 / 75$ & 78 & 100 & \\
\hline 30 & $138 / 77$ & 82 & 100 & Endotracheal intubation \\
\hline 40 & $180 / 98$ & 86 & 100 & \multirow{2}{*}{$\begin{array}{l}\text { No larynx reflex, no tear and sweat. } \\
\text { Pupils'size was } 3 \mathrm{~mm} \text { wide. Responsive to light }(+) \text {. Slowly injecting } 1 \mathrm{mg} \\
\text { of nicardipin }\end{array}$} \\
\hline 45 & $210 / 105$ & 87 & 100 & \\
\hline 60 & $140 / 81$ & 85 & 100 & \\
\hline 150 & $135 / 76$ & 88 & 100 & Recovered \\
\hline
\end{tabular}


In this patient, the hypotensive effect of spinal anesthesia might be exacerbated by Parkinson's disease. Parkinson's disease is a neurodegenerative condition characterized by increased activity of GABA in basal ganglia and the loss of dopamine in nigrostriatum. This changes lead to the progressive deterioration of motor function due to the loss of dopamine-producing brain cells. Patients who are on chronic dopaminergic therapy as a treatment for Parkinson disease may also experience vasodilation and systemic hypotension. One of the features that occur in patients with Parkinson's disease is orthostatic hypotension. This condition may exacerbate the hypotensive effect of spinal anesthesia and caused systolic blood pressure to decrease sharply in this patient after the procedure. According to Alkaya et al, spinal anaesthesia is generally not preferred in patients with neurological diseases [7], due to the risk of exacerbation of orthostatic hypotension. In contrast, Oğuz et al. reported that spinal anaesthesia does not pose an absolute or a relative contraindication and can be safely and effectively used in Parkinson's patients [8]. However, patients should be monitored carefully perioperatively.

In summary, complete spinal block may happen even with low- dose bupivacaine. Preventive measurments should be on stand-by after spinal anesthesia and anesthetists should be aware of this complication, especially in elderly patients.

\section{References}

1. Barash PG, Cullen BF, Stoelting RK (2007) Epidural and Spinal anesthesia, Clinical Anesthesia, Lippincott Williams \& Wilkins, USA, 700-705.

2. Lamacraft $\mathrm{G}$ (2004) Complications associated with regional anesthesia for Ceasarean section. Southern African Journal of Anesthesia \& Analgesia 15-20.

3. David pescod (2007) "Developing anesthesia text book", 206.

4. Bhati FS, Vijayvergia VK, Jain VL (2004) Loss of consciousness following spinal anesthesia for caesarean section. Indian Journal of Anaesthesia 48: 57-58.

5. Chan YK, Gopinathan R, Rajendram R (2000) Loss of consciousness following spinal anaesthesia for caesarean section. Br J Anaesth 85: 474-476. [Crossref]

6. Tarkkila P (2007) Complication Associated with Spinal Anesthesia, Complications of Regional Anesthesia, Springer Science+Business Media, USA, 149-166.

7. Alkaya F, Kirdemir P, Atay T (2012) Regional anesthesia for parkinson Disease: Case report. Turkish Journal of Geriatrics 15: 473-5.

8. Oguz E,Ozturk I, Ozkan D, Ergil J, Aydin GB (2014) Parkinson's Disease and Spinal Anaesthesia. Turk J Anaesth Reanim 42: 280-2.

Copyright: $(02015$ Kien NT. This is an open-access article distributed under the terms of the Creative Commons Attribution License, which permits unrestricted use, distribution, and reproduction in any medium, provided the original author and source are credited. 